\title{
Consultative Committee for Space Data Systems
}

\section{Introduction}

The major space agencies of the world recognize that there are benefits in using standard techniques for handling space data and that, by cooperatively developing these techniques, future data system interoperability will be enhanced. In order to assure that work towards standardization of space-related information technologies provides the maximum benefit for the interested agencies, both individually and collectively, an international Consultative Committee for Space Data Systems (CCSDS) was established in 1982 as a forum for international cooperation in the development of data handling techniques supporting space research, including space science and applications. In 1991, the committee was incorporated as a subcommittee of the International Organization for Standardization (ISO).

The original participants in the development and approval of the CCSDS Charter were CNES (France), DLR (Germany, at that time DFVLR), ESA (Europe), ISRO (India), INPE (Brazil), NASA (USA), JAXA (Japan, at that time NASDA). The Charter was updated in May 1999 and again in September 2004. It should be noted that the revisions of the charter were essentially re-organizations of the working methods and not changes to topics to be addressed.

\section{Origins and Development}

As the space age evolved in the 1960s and 1970s, there was increasing interest in stimulating international cooperation as a way to enhance space exploration. In particular, since many space agencies had invested large sums of money in the development of space mission support infrastructure on the ground, the concept of 'cross support' emerged whereby one agency could offer its data handling services to another and thus enhance the opportunities for conducting international missions. During those early days, in the absence of any internationally agreed space data standards, cross support was generally handled by the introduction of 'black box' adapters to forge compatibility at the interfaces between agencies. These black boxes were uniquely configured for each individual case. 
As space exploration moved along into the 1980s, technological advances in spacecraft computation, memory, and communications capabilities made it feasible to start standardizing the ways in which spacecraft and ground data systems exchanged information. At the same time, the costs of implementing and operating these more capable space missions were increasing significantly. To take advantage of the opportunities presented by the technological advances and to meet the fiscal challenges, some initial steps were taken which ultimately lead to the

formation of the CCSDS. In March 1981, the NASA-ESA Working Group (NEWG) held its first meeting to address cooperative development of space data standards, initially in the areas of spacecraft 'packet telemetry' (technology that allows the remote measurement and receipt of information) and then in 'packet telecommand' (technology that allows a system to be remotely operated by sending information and instructions to it). In January 1982, at an International Workshop on Space Data Systems held in Washington, D.C., this bilateral activity was broadened and many of the world's space agencies met to begin discussing common problems relative to space information and data systems. At that meeting, the final steps were taken to formalize international space data standardization activities by creating the CCSDS, which then had its inaugural meeting at CNES in Toulouse, France on 4-8 October 1982.

The CCSDS was chartered to study the problems of cross support and, through the collective efforts of its international experts, to develop advanced standardized solutions to these challenges of exchanging space mission data. These solutions, called CCSDS Recommendations, were the primary products of the CCSDS for most of its first 20 years. Draft CCSDS Recommendations were created, reviewed by CCSDS participating agencies and were subsequently adopted by the CCSDS participating agencies as final CCSDS Recommendations that served to guide the internal development of standards by each of the members. These early CCSDS activities significantly enhanced the planning and execution of cooperative space missions flown by the participating agencies.

The initial structure of CCSDS, adopted in 1982, centred around technical 'panels' to develop standard Recommendations in various space data system areas. The initial structure was:

- Panel 1: Telemetry, Tracking, and Command;

- Panel 2: Information Interchange Processes;

- Panel 3: Cross Support Operations; and

- Panel 4: Radio-metric and Orbit Data. 
The space-to-ground data link was the first part of the data system to be addressed by CCSDS, primarily because it is unique to space missions and is constrained by the stressed communications environment. Based on the precursor work by NASA and ESA, CCSDS Panel 1 soon presented concrete results in the form of two final CCSDS Recommendations, one for 'Packet Telemetry' and one for 'Telemetry Channel Coding'. Panel 1 quickly followed through with standards for space channel modulation, packet telecommand, time code formats and - by the end of the 1980s - with the 'advanced orbiting systems' standards that became the data communications baseline for the International Space Station. Meanwhile, Panel 2 rapidly developed new standards for exchanging information among scientific and engineering users; Panel 3 began developing the 'space link extension' standards that could allow one agency's control centre to connect to another agency's ground station; and Panel 4 developed standards for exchanging radio-metric information.

In 1991, the CCSDS entered into a cooperative arrangement with the International Organization for Standardization. Under this arrangement, CCSDS Recommendations were advanced to Subcommittee 13 within Technical Committee 20 (Aircraft and Space Vehicles) where, via the normal ISO procedures of review and voting, they are progressed into full International Standards.

\section{Membership}

Four types of participation exist within the CCSDS: Members (11); Observers (26); Liaisons (12); and Associates (>100). While within CCSDS space agencies are the building blocks, in ISO the specific countries are the voting bodies. At first sight this might seem to be problematic, but apart from ESA, the representatives of the national space agencies are also the national representatives of the standardization bodies in ISO.

\section{Member Agencies}

A CCSDS Member Agency is a governmental or quasi-governmental organization that fully participates in all CCSDS activities and provides a commensurate level of support. Only one agency representing a given country or multinational organization may participate as a Member Agency of the CCSDS. A Member Agency adopts the Charter and must ensure that their agency enforces internal standards to the applicable CCSDS Recommended Standards. 
Member Agencies have CCSDS voting rights, which are exercised through Member Agency Representatives. Member Agency Representatives make up the CCSDS Management Council (CMC), where decisions on the business and direction of the CCSDS are taken.

In 2009, the following 11 agencies were members of CCSDS: ASI (Italy), BNSC (Great Britain), CNSA (China National Space Administration), CSA (Canada), CNES (France), DLR (Germany), ESA (Europe), FSA (Russia), INPE (Brazil), JAXA (Japan), and NASA (USA).

\section{Observer Agencies}

26 governmental or quasi-governmental organizations participate in CCSDS activities at a reduced level as Observer Agencies. They are encouraged but not expected to make best efforts to ensure the adherence of their agency's internal standards to the applicable CCSDS Recommended Standards. There is no limit on the number of national or multinational agencies that may participate as Observer Agencies.

\section{Liaisons}

Liaison organizations are governmental or private entities with developmental programmes in the areas of space-related data and information systems. When Liaison participation occurs, it is usually focused on a particular subject of interest to the Liaison organization. In 2008, the organizations with agreements or pending agreements with CCSDS were:

- American Institute for Aeronautics and Astronautics;

- CEOS;

- COSPAR;

- European Committee for Space Standardization (ECSS);

- Interagency Operations Advisory Group (IOAG);

- International Society for Photogrammetry and Remote Sensing;

- ISO/IEC JTC 1 SC 2;

- National Archives and Records Administration;

- National Information Standards Organization;

- Norwegian Technology Standards Institution;

- Object Management Group Inc.; and

- World Meteorological Organization.

\section{Associates}

Associates include more than 100 scientific and industrial entities that aim to more closely monitor and possibly influence the technical document development process in CCSDS. 


\section{Organizational Structure}

In 2003, after more than 20 years of success, and recognizing the need to streamline and broaden its processes, the CCSDS went through a structural re-organization based on a model that was used successfully by the Internet Engineering Task Force (IETF) to develop the terrestrial Internet. Within the new CCSDS organization, six broad discipline 'Areas' were created:

- System Engineering Services;

- Mission Operations and Information Management Services;

- Cross Support Services;

- Spacecraft Onboard Interface Services;

- Space Link Services; and

- Space Internetworking Services

Within each of these Areas, specialized Working Groups were created to develop 'Recommended Standards' which are normally transferred into ISO standards. Additional categories of 'Recommended Practices' and 'Experimental' standards were also added to the specification hierarchy.

\section{Management Structure}

As outlined above, the CCSDS consists of Member Agencies, Observer Agencies, Associates and Liaisons. The CCSDS Management Council (CMC) is the executive management oversight group of the organization. The CMC is comprised of the Member Agencies who each appoint one Principal Delegate. These Members select the CMC chairman on a rotating basis, although in practice, the rotation is activated less frequently than it should be. The CMC is responsible for staying technically and politically informed about important long-term issues in the field of international space mission cross support and for keeping an eye on the 'big picture' of the CCSDS programme of work. It therefore focuses on long-range planning and coordination among the various CCSDS discipline-oriented domains, on making sure that adequate resources exist to do work, and that customer requirements are satisfied in a timely manner.

The CCSDS Engineering Steering Group (CESG) is the forum in which the Area Directors synchronize the overall technical programme of work. The CESG reports to the CMC, and is divided into three 'domains' - space telematics; space systems; and space informatics. The space telematics domain covers three areas: spacecraft onboard interface services; space link services; and space internetworking services. The space systems domain is concerned with systems engineering, while the space informatics domain deals with mission operations and information management, as well as cross support 
services. These domains are supported through the establishment of the following entities:

- Birds-of-a-Feather groups (BOFs) - perform start-up studies and gestate technical proposals to the point where establishment of a Working Group may be decided.

- Working Groups (WGs) - are established to produce standards on a specific schedule and within specific resource envelopes, and then go out of business.

- Areas that contain WGs and BOFs that are closely related to a particular technical discipline, under the coordination of an expert Area Director.

\section{Financing}

Resources for space standardization work are shared by national, regional, and international standardization efforts. Depending on the level of interest in the standard under development, agencies may decide to fund additional effort. All of the secretarial, administrative, technical, and infrastructural support is funded by the Agency that holds the CCSDS chair in a given year.

\section{The Role of the CCSDS in Transnational Economic Governance}

The objectives of the CCSDS are:

- to provide a forum whereby interested agencies may exchange technical information relative to the development or application of standards for space-related information technologies;

- to identify those common elements of space data systems which, if implemented in a standardized way, will result in significant enhancements in the operation of future cooperative space missions, or in the sharing of mission products;

- to develop through consensus appropriate standards that will guide the development of agency infrastructure so that interoperability is maximized;

- to facilitate and promote the use of software and hardware developed under the CCSDS programme by all participating agencies;

- to promote the application of the standards within the space mission community; and

- to maintain cognizance of other international standardization activities that may have direct impact on the design or operation of space mission data systems. 


\section{International Standardization and the Role of ISO}

The foremost aim of international standardization is to facilitate the exchange of goods and services through the elimination of technical barriers to trade. For space standardization three bodies are responsible for the planning, development, and adoption of International Standards: ISO is responsible for all sectors excluding Electrotechnical, which is the responsibility of the IEC (International Electrotechnical Commission), and most of the Telecommunications Technologies, which are largely the responsibility of the ITU (International Telecommunication Union).

ISO is a legal association, the members of which are the National Standards Bodies (NSBs) of some 130 countries (organizations representing social and economic interests at the international level), supported by a Central Secretariat based in Geneva, Switzerland (see ISO entry in this Handbook). The principal deliverable of ISO is the International Standard. It should be noted here that in many cases these standards are adopted as national standards (such as the German DIN). An International Standard embodies the essential principles of global openness and transparency, consensus, and technical coherence. These are safeguarded through its development in an ISO Technical Committee (ISO/TC), representative of all interested parties, supported by a public comment phase (the ISO Technical Enquiry). ISO and its Technical Committees are also able to offer the ISO Technical Specification (ISO/TS), the ISO Public Available Specification (ISO/PAS) and the ISO Technical Report (ISO/TR) as solutions to market needs. These ISO products represent lower levels of consensus and therefore do not have the same status as an International Standard.

ISO also offers the Industry Technical Agreement (ITA) as a deliverable that aims to bridge the gap between the activities of consortia and the formal process of standardization represented by ISO and its national members. An important distinction is that the ITA is developed by ISO workshops and fora, comprising only participants with direct interest, and so it is not accorded the status of an International Standard.

\section{Background and Scope of the ISO/TC-20 Space Systems}

Within the scope of the Technical Committee for Aircraft and Space Vehicles (TC-20), two subcommittees were formed with responsibility for all ISO work in the area of standards for space systems. These subcommittees were the Space Data and Information Transfer Systems (SC-13), formed in 1990 (which is technically the CCSDS) and the Space Systems and Operations (SC-14), formed in 1995. The area of responsibility for these subcommittees includes: 
- Protocols for the data links that unite the space elements, the ground elements and the users (SC-13); and

- Design, test, operations, and ground support for space vehicles and their attendant systems (SC-14).

Responding to the needs of an increasingly commercial and global space business these subcommittees have established a significant portfolio of standards. At the start of 2004 some standards were published or in the formal voting stage and several were in the drafting stages. To better align a growing work programme with business needs and trends and to manage an expanding portfolio of standards both subcommittees have introduced major internal organizational processes. Today the management and operation of these subcommittees reflects a scale and level of maturity comparable with that of a full Technical Committee.

\section{Trends and Challenges}

To accommodate the future, changes in TC-20 are under discussion. Changing institutional and commercial markets for space products and services are predicted to require even greater emphasis on standardization reflecting both an increasingly global market and the nature of space as an international resource. Major new initiatives are being proposed for Telecommunications, Space Science and Exploration, Navigation, Global Monitoring, Defence, and Security. Commercial development and technology advances are also predicted to drive the need for new space standards; for example, the increasing capability of small satellites allied to micro systems technology and a potential paradigm shift in the development of low cost systems. Further reflecting the international dimension, new standards are being initiated by SC-14 to mitigate against future increases in space debris which, if unchecked, could prevent access to some orbits with high scientific and commercial potential.

Taking these and many other factors into consideration, SC-14 considered the value of transitioning the subcommittee to a full Technical Committee focused on space. As a consequence of this debate and on-going consultations, a resolution was passed in May of 2003 to transition SC-14 into a full Technical Committee. During these consultations, SC-13 became supportive of the proposal and from November 2003 the two subcommittees combined their efforts in promoting a new Technical Committee for Space Systems. 


\section{Bibliography}

The section on Origins and Development is largely excerpted from articles by Dr Horst Kummer (formerly of ESA), Mr Robert Stephens (formerly of NASA), and Mr Edward Greene (formerly CCSDS Secretariat and formerly of NASA); The remaining sections are largely taken from: ISO/TC-999 Business Plan, February 2005, Draft Revision 4; and Restructured Organization and Processes for the CCSDS, CCSDS A02.1-Y-2, April 2004.

\section{Contact}

CCSDS Outreach and Public Affairs 1801 Alexander Bell Drive, Suite 500 Reston, VA 20191-4344

USA

Tel: + 17032643849

Fax: + 17032647551

Email: craigd@aiaa.org

Web: public.ccsds.org 
